\title{
GATA augments GNRH-mediated increases in Adcyap1 gene expression in pituitary gonadotrope cells
}

\section{Robin L Thomas, Natalie M Crawford, Constance M Grafer, Weiming Zheng and Lisa M Halvorson}

Division of Reproductive Endocrinology and Infertility, Department of Obstetrics and Gynecology, University of Texas Southwestern Medical Center, 5323 Harry Hines Boulevard, Dallas, Texas 75390-9032, USA
Correspondence should be addressed to L M Halvorson Email

lisa.halvorson@ utsouthwestern.edu

\begin{abstract}
Pituitary adenylate cyclase-activating polypeptide 1 (PACAP or ADCYAP1) regulates gonadotropin biosynthesis and secretion, both alone and in conjunction with GNRH. Initially identified as a hypothalamic-releasing factor, ADCYAP1 subsequently has been identified in pituitary gonadotropes, suggesting it may act as an autocrine-paracrine factor in this tissue. GNRH has been shown to increase pituitary Adcyap1 gene expression through the interaction of CREB and jun/fos with CRE/AP1 cis-elements in the proximal promoter. In these studies, we were interested in identifying additional transcription factors and cognate cis-elements which regulate Adcyap1 gene promoter activity and chose to focus on the GATA family of transcription factors known to be critical for both pituitary cell differentiation and gonadotropin subunit expression. By transient transfection and electrophoretic mobility shift assay analysis, we demonstrate that GATA2 and GATA4 stimulate Adcyap1 promoter activity via a GATA cis-element located at position - 191 in the rat Adcyap1 gene promoter. Furthermore, we show that addition of GATA2 or GATA4 significantly augments GNRHmediated stimulation of Adcyap1 gene promoter activity in the gonadotrope L $\beta T 2$ cell line. Conversely, blunting GATA expression with specific siRNA inhibits the ability of GNRH to stimulate ADCYAP1 mRNA levels in these cells. These data demonstrate a complex interaction between GNRH and GATA on ADCYAP1 expression, providing important new insights into the regulation of gonadotrope function.
\end{abstract}

\section{Key Words}

- adenylate cyclase-activating polypeptide 1

- GATA

- gonadotropes

- PACAP

pituitary
Journal of Molecular

Endocrinology

(2013) 51, 313-324

\section{Introduction}

Proper functioning of the hypothalamic-pituitary-gonadal axis requires the complex interplay of gonadotropinreleasing hormone (GNRH), steroids, and other regulatory factors. In addition to the well-characterized effects of hypothalamic GNRH, the neuropeptide adenylate cyclaseactivating polypeptide 1 (ADCYAP1; also known as PACAP) also regulates gonadotropin gene expression.
ADCYAP1 is secreted by hypothalamic neurons into the pituitary portal vasculature, binding to specific $G$ proteincoupled receptors on pituitary cell membranes and activating the cAMP/protein kinase A signaling pathway (Sherwood et al. 2000, Vaudry et al. 2000). ADCYAP1 increases gonadotropin biosynthesis and secretion, alone and in synergy with GNRH (Culler \& Paschall 1991,

Published by Bioscientifica Ltd. 
Schomerus et al. 1994, Tsujii \& Winters 1995, Winters et al. 1996, Purwana et al. 2010, Kanasaki et al. 2013). ADCYAP1 has been shown to increase $\alpha$-subunit, Lhb, Fshb, and Gnrhr gene promoter activity and mRNA levels in gonadotropes (Schomerus et al. 1994, Tsujii \& Winters 1995, Winters et al. 1996, Burrin et al. 1998, Katayama et al. 2000, Cheng \& Leung 2001, Ngan et al. 2001, Pincas et al. 2001b, Fujii et al. 2002, Ferris et al. 2007, Purwana et al. 2010). Although less potent than GNRH, ADCYAP1 also stimulates luteinizing hormone (LH) and follicle-stimulating hormone (FSH) secretion by primary pituitary cells and the gonadotrope cell line, $\alpha$ T3-1 (Culler \& Paschall 1991, Hart et al. 1992, Perrin et al. 1993, Schomerus et al. 1994, Tsujii \& Winters 1995, Winters et al. 1996, Koves et al. 2003). These stimulatory effects of ADCYAP1 on LH secretion in rats have been confirmed in vivo (Osuga et al. 1992, Radleff-Schlimme et al. 1998). GNRH and ADCYAP1 exert cooperative effects on gonadotrope function via multiple mechanisms including alterations in receptor expression. As shown by Kanasaki et al. (2009), treatment of gonadotrope cells with either pulsatile GNRH or ADCYAP1 stimulates both GNRH receptor (GNRHR) and PACAP receptor type 1 (Adcyap1r1) gene expression.

Although, originally identified as a hypothalamicreleasing factor, ADCYAP1 subsequently has been determined to have widespread distribution and function, including expression in the CNS and peripheral nervous system, smooth muscle, adrenal gland, placenta, anterior and posterior pituitary, ovaries, and testes (Arimura \& Shioda 1995). Within the anterior pituitary gland, both gonadotropes and the folliculostellate cells have been shown to synthesize and secrete ADCYAP1 peptide (Koves et al. 1998, Jin et al. 2001, Szabo et al. 2002, Heinzlmann et al. 2008). Therefore, ADCYAP1 both acts on and is secreted by pituitary cells, forming a functional autocrineparacrine loop in this tissue.

A limited number of studies have begun to elucidate the hormonal factors which regulate Adcyap1 gene expression. Estradiol and progesterone have been suggested to stimulate Adcyap1 expression in the hypothalamus and ovary (Ha et al. 2000, Park et al. 2000, Apostolakis et al. 2004, Moore et al. 2005). Additional studies have shown the ability of LH and FSH to promote Adcyap1 expression in human granulosa-luteal cells obtained from patients undergoing IVF (Morelli et al. 2008). LH, FSH, human chorionic gonadotropin, and GNRH have also been shown to increase Adcyap1 mRNA levels in the ovary (Ko et al. 1999, Lee et al. 1999, Park et al. 2001).

GNRH has also been demonstrated to increase ADCYAP1 biosynthesis in the pituitary. As shown by our group and others, Adcyap1 promoter activity and mRNA levels are markedly increased by static or pulsatile GNRH treatment in an immortalized gonadotrope cell line (Grafer et al. 2009, Purwana et al. 2010, Kanasaki et al. 2011). This stimulatory effect has been confirmed in rat primary pituitary cell cultures in which a threefold increase in Adcyap1 mRNA levels has been observed in response to GNRH treatment (C M Grafer and L M Halvorson, 2009, unpublished observations). We have reported that the GNRH response is mediated via the PKA, PKC, and MAPK intracellular signaling pathways acting via three DNA-regulatory elements, a CRE site located at position -205 and two AP1 sites located at positions -275 and -448 , in the proximal Adcyap1 promoter (Grafer et al. 2009). Furthermore, these studies demonstrated a role for CREB and the AP1 proteins, jun and fos, in mediating this response. This work was the first to identify specific transcription factors and associated cis-elements with the importance for pituitary Adcyap1 gene expression. We, therefore, were interested in identifying additional transcription factors with the importance for expression of this gene.

The GATA family of transcription factors has been shown to regulate gene expression at all levels of the reproductive axis. Although originally characterized in the hematopoietic and cardiac systems, GATA factors are now known to be expressed in hypothalamic GNRH neurons, the pituitary, the ovary, and the testes (LaVoie 2003, Viger et al. 2008). Vertebrates express six different GATA family members. The amino acid sequence of these factors is highly conserved with $\sim 80 \%$ homology in the zinc finger DNA-binding domains. As indicated by their name, the GATA factors bind to the consensus motif GATA, although they have also been reported to bind nucleotide sequences containing core GATC or GATT elements (Merika \& Orkin 1993, Nakagawa et al. 2001).

Within the pituitary gland, GATA transcription factors have been shown to be critical for both pituitary cell differentiation and function. During development, GATA2 directs cells toward the gonadotrope lineage and away from the thyrotrope lineage through reciprocal interactions with Pit1 (Dasen et al. 1999). Functional GATA cis-elements have also been identified in the promoter regions of the common $\alpha$ - and Fshb-subunit genes, as well as the Gnrh gene (Steger et al. 1994, Pincas et al. 2001a, Lo et al. 2011). Our laboratory has recently demonstrated that the adult mouse pituitary expresses GATA4 in addition to GATA2 and that both of these factors stimulate gonadotropin $L h b$ gene expression in the LBT2 gonadotrope cell line (Lo et al. 2011).

Published by Bioscientifica Ltd. 
For the studies reported here, we hypothesized that GATA transcription factors play a role in the regulation of Adcyap1 gene expression in pituitary gonadotropes. Our results demonstrate the ability of both GATA2 and GATA4 to stimulate basal and GNRH-induced Adcyap1 gene expression via a GATA response element located at position -191 relative to the transcriptional start site in the proximal rat Adcyap1 gene promoter.

\section{Subjects and methods}

\section{RNA extraction and RT}

Total RNA was prepared from cultured gonadotrope L $\beta$ T2 cells using TRI Reagent (Ambion, Inc., Austin, TX, USA) according to the manufacturer's instructions. Total RNA samples were DNase-treated using the Turbo DNA-free Kit (Ambion, Inc.) and reverse transcribed using Superscript II reverse transcriptase (Invitrogen, Inc.) primed with random hexamer. A parallel reaction lacking RT was used as an additional negative control. L $\beta$ T2 cells were generously provided by Dr P L Mellon (University of California, San Diego, CA, USA).

\section{Quantitative real-time PCR}

cDNA (10-100 ng/reaction) was amplified in triplicate in a 384-well plate on a 7900HT Sequence Detection System (Applied Biosystems) using Applied Biosystems TaqMan Universal PCR Master Mix and gene-specific TaqMan Gene Expression Assay primer/probe sets with universal cycling conditions (Table 1). Each reaction was run in $15 \mu \mathrm{l}$ total volume. The expression of each target gene was normalized to $18 \mathrm{~S}$ transcript expression in each sample. The relative target gene expression levels among treatments were calculated using the comparative $C_{\mathrm{T}}$ method as described in Applied Biosystems User Bulletin No. 2.

Table 1 PCR primers used in this study

\begin{tabular}{l} 
Name of oligonucleotides \\
\hline EMSA \\
WT $(-209 /-167)$ \\
Mutant -191 GATA \\
Mutant -205 CRE \\
Mutant -179 CRE \\
Mutant $-205 /-179$ CRE \\
Mutagenesis \\
Mutant -191 GATA \\
Mutant -191 GATA/-205 CRE \\
Mutant -191 GATA/-179 CRE \\
Mutant -191 GATA/-205 CRE/-179 CRE
\end{tabular}

http://jme.endocrinology-journals.org DOI: $10.1530 / J M E-13-0089$

\section{Plasmids}

The rat Adcyap1 gene promoter spanning region -1916 to +906 relative to the transcription start site exon 1A (gene ID: 24166) was subcloned into the pGL3-Basic luciferase reporter vector (Promega) (cDNA was kindly provided by Drs S L White and $\mathrm{K}$ M Braas (University of Vermont College of Medicine, Burlington, VT)). A CRE site mutant (mutCRE(-205)) was also provided containing an AC to TG mutations present at position -203 . Additional deletion constructs and site-directed mutations were generated by the PCR or the QuikChange Site-directed Mutagenesis Kit (Stratagene, La Jolla, CA, USA). The fidelity of all constructs was verified by nucleotide sequencing. The cDNAs encoding mouse GATA2 and GATA4 were provided by D F Gordon and S Hammes, respectively, and were subcloned into pcDNA3.1(+) (Invitrogen, Inc.).

\section{Transient transfection of cell lines}

Green monkey kidney fibroblast cells (CV1) were maintained in monolayer culture in low glucose DMEM supplemented with $10 \%$ fetal bovine serum (FBS) (v/v) and $1 \%$ penicillin/streptomycin $(\mathrm{v} / \mathrm{v})$ at $37^{\circ} \mathrm{C}$ in humidified $5 \% \mathrm{CO}^{2} / 95 \%$ air. CV1 cells $\left(6-7 \times 10^{4}\right.$ cells/well) were cultured overnight in 12-well plates. Using the calcium phosphate precipitation method, each well was transfected with $400 \mathrm{ng} /$ well of ADCYAP1 reporter vector and 0-30 ng/well of GATA2 or GATA4 expression vectors as indicated in the dose-response experiment (Fig. 1). For subsequent CV1 experiments, cells received $30 \mathrm{ng}$ of GATA2 and 10 ng of GATA4 expression vector. The GATA response of the empty luciferase reporter vector was less than threefold (data not shown).

For LßT2 transfection experiments, cells were maintained in high glucose DMEM supplemented with
Sequences (mutated residues underlined)

5'-ATGCTGACGTCTTTTACTGATACCGGATCATTACGTGACTGGG-3' 5'-ATGCTGACGTCTTTTTACTGCCACCGGATCATTACGTGACTGGG-3' 5'-ATGCTGTGGTCTTTTACTGATACCGGATCATTACGTGACTGGG-3' 5'-ATGCTG $\overline{A C G T C T T T T A C T G A T A C C G G A T C C T T T G G T G A C T G G G-3 ' ~}$ 5'-ATGCTGTGGTCTTTTACTGATACCGGATCC̄TTTGGTGACTGGG-3'

5'-GATGCTGACGTCTTTTACTGCCACCGGATCATTACGTGACT-3' 5'-GATGCTGTGGTCTTTTACTG CCACCGGATCATTACGTGACT-3' 5'-GGATGCT $\overline{G A} C G T C T T T T A C T \overline{G C} C A C C G G A T C C T T T G G T G A C-3^{\prime}$ 5'-GGATGCTGTGGTCTTTTACTGCCACCGGATCC̄TTTGGTGAC-3' 


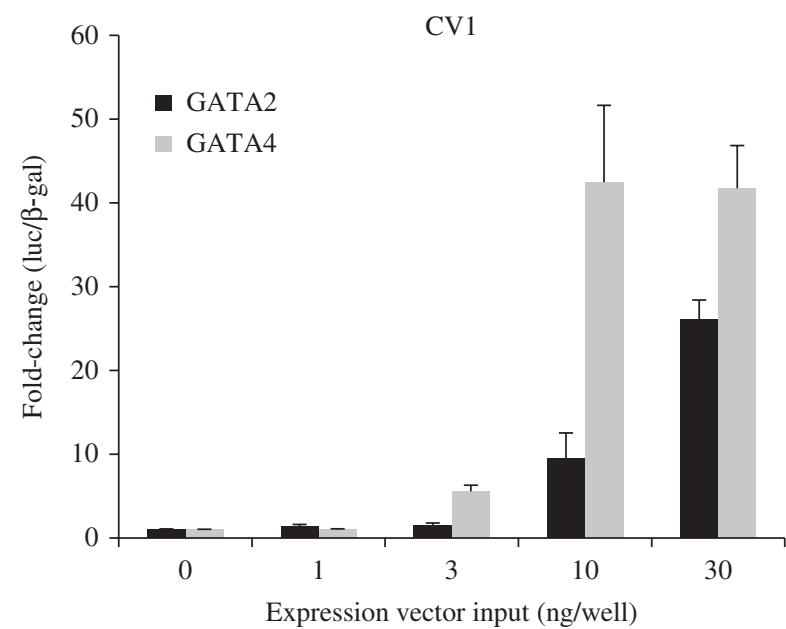

Figure 1

GATA2 and GATA4 stimulate Adcyap1 promoter activity in a dosedependent fashion. Fibroblast CV1 cells were transiently transfected with a reporter construct containing region -1916/ + 906 of the rat Adcyap1 gene promoter fused to a luciferase reporter, pGL3. Cells were cotransfected with the indicated amount of expression vector for either GATA2 or GATA4 and with the pSV- $\beta$-galactosidase vector to control for differences in transfection efficiency. Luciferase activity was normalized to $\beta$-galactosidase activity and expressed as fold-change relative to cells receiving the same amount of empty expression vector. All experiments were performed a minimum of three times with data expressed as the mean \pm s.E.M.

10\% FBS (v/v), 1\% penicillin/streptomycin (v/v), and $1 \mathrm{mM}$ sodium pyruvate. Cells $\left(2.5-3 \times 10^{5}\right.$ cells/well $)$ were grown overnight in antibiotic-free media in 12-well plates. The cells were then transfected with $400 \mathrm{ng} /$ well of ADCYAP1 reporter vector and $100 \mathrm{ng} /$ well of GATA2 or GATA4 expression vectors or empty-vector control using the FuGENE 6 Transfection Reagent (Roche Applied Sciences) and OptiMEM-1 Reduced Serum Medium (Invitrogen, Inc.) according to the manufacturer's instructions. The day following transfection, cells received fresh antibiotic-free DMEM. Cells were treated for $6 \mathrm{~h}$ with the GNRH analog $\left[\right.$ des-Gly ${ }^{10}$, D-Ala ${ }^{6}$ ]-LH-RH ethylamide acetate hydrate (10 nM or as indicated; Sigma-Aldrich) or vehicle before harvest. Cotransfection of L $\beta$ T2 and CV1 cells with $48 \mathrm{ng} /$ well of a pSV- $\beta$-galactosidase plasmid (Promega) allowed correction for differences in transfection efficiency within the experiments. Cells were harvested at $\sim 48 \mathrm{~h}$ following transfection and the cell extracts were analyzed for luciferase activity and for $\beta$-galactosidase activity using the Galacto-Light Plus assay system (Tropix, Applied Biosystems) and a luminometer from Berthold Detection Systems (Pforzheim, Germany). Luciferase activity was normalized to $\beta$-galactosidase activity and results were calculated as fold-changes relative to expression in the control wells.
Data are shown as the mean \pm s.E.M. from at least three experiments with three replicates performed within each experiment.

\section{siRNA interference}

For siRNA experiments, L $\beta$ T2 cells were seeded onto 12-well plates at $2.5 \times 10^{5}$ cells/well in DMEM containing 10\% FBS (without antibiotics) one day before siRNA transfection. Dharmacon ON-TARGET plus SMARTpool siRNAs directed toward mouse Gata2 (L-062114-00-0005) or Gata4 (L-040759-01-0005) or a nontargeting negative control (D-001810-10-05) was transfected into L $\beta$ T2 cells using DharamaFECT-1 siRNA Transfection Reagent (Thermo Fisher Scientific, Lafayette, CO, USA). Each well was transfected with $1 \mathrm{ml}$ of $100 \mathrm{nM}$ siRNA diluted in OptiMEM-1 Reduced Serum Medium (Invitrogen, Inc.), complexed with $3 \mu$ l DharmaFECT-1. The cells were cultured overnight and the transfection mixture was replaced the next day with DMEM containing 10\% FBS. After treatment for the final $6 \mathrm{~h}$ with $100 \mathrm{nM}$ GNRH or vehicle control, the cells were harvested $48 \mathrm{~h}$ after transfection for total RNA isolation for quantitative real-time PCR (qPCR) analysis. Each combination of siRNA and hormonal treatment was tested in duplicate in three experiments.

For each experiment, qPCR data was calculated using the comparative $C_{\mathrm{T}}$ method and calibrator values were chosen to set the averages of replicate vehicle-treated or GNRH-treated, non-targeting (NTA) siRNA samples equal to 100 . The various experimental vehicle-treated or GNRH-treated samples were then expressed relative to their appropriately treated NTA controls.

\section{Statistical analysis}

Statistical analysis was performed using the SigmaStat Software Package (SPSS Science). Data were analyzed for normality followed by ANOVA. The Tukey's test was used for post hoc comparisons. The $t$-test was used where only two groups were involved. Statistical significance was set at $P<0.05$.

\section{Results}

\section{GATA2 and GATA4 stimulate Adcyap1 gene promoter activity in CV1 cells}

In order to study the effects of GATA transcription factors on Adcyap1 promoter activity, transient transfection of the full-length rat Adcyap1 $(-1916 /+906)$ gene promoter

Published by Bioscientifica Ltd. 
fused to the pGL3 luciferase reporter was conducted in CV1 cells. These cells are an immortalized green monkey kidney fibroblast cell line essentially devoid of any endogenous GATA (Robert et al. 2006). Dose-response

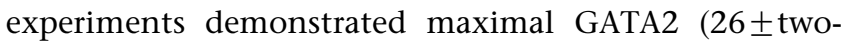
fold) stimulation of full-length rat Adcyap1 gene promoter activity at $30 \mathrm{ng} /$ well and maximal GATA4 ( $42 \pm$ nine-fold) stimulation of full-length rat Adcyap1 gene promoter activity at $10 \mathrm{ng} /$ well (Fig. 1). These maximal doses were chosen for subsequent transfection experiments in the CV1 cell line.

\section{The GATA response maps to positions -242 to -172 of the rat Adcyap1 gene promoter}

We next wished to determine the region of the Adcyap1 gene promoter that confers GATA responsiveness. Transient transfection of serial $5^{\prime}$ deletions of the rat Adcyap1 gene demonstrated a dramatic loss of GATA2 and GATA4 responsiveness between nucleotide positions -402 and -77 (79 \pm 2 and $89 \pm 2 \%$, respectively, compared with the -1916/+906 Adcyap1 promoter construct; Fig. 2A). A significant loss of GATA4 responsiveness was also observed with deletion between positions -915 and -402 (Fig. 2A). We chose to focus on the downstream region as it conferred both GATA2 and GATA4 effects.

As shown in Fig. 2B, a series of intermediate 5 '-truncations between region -402 and -77 were tested to further localize the GATA-responsive region. Both the GATA2 and GATA4 responses were significantly decreased with deletion between positions -242 and $-172(80 \pm 9$ and $72 \pm 6 \%$, respectively, compared with the $-402 /+906$ Adcyap1 promoter construct).

\section{Identification of a putative GATA binding site in the rat Adcyap1 gene promoter}

By sequence homology, three GATA-like elements, located at positions $-210,-191$, and -184 , were identified within region -242 to -172 . By electrophoretic mobility shift assay (EMSA), in vitro translated and endogenous L $\beta$ T2, GATA2, and GATA4 proteins did not bind to a nucleotide probe spanning either position -210 or -184 (data not shown). However, as shown in Fig. 3B, in vitro translated GATA2 and GATA4 (lanes 2 and 4 respectively) bound to the WT probe spanning position -191 . The presence of GATA2 or GATA4 in the identified complex was confirmed by the addition of specific antibodies for the corresponding protein (lanes 3 and 5). Endogenous GATA2 and GATA4 present in L $\beta$ T2 nuclear extracts
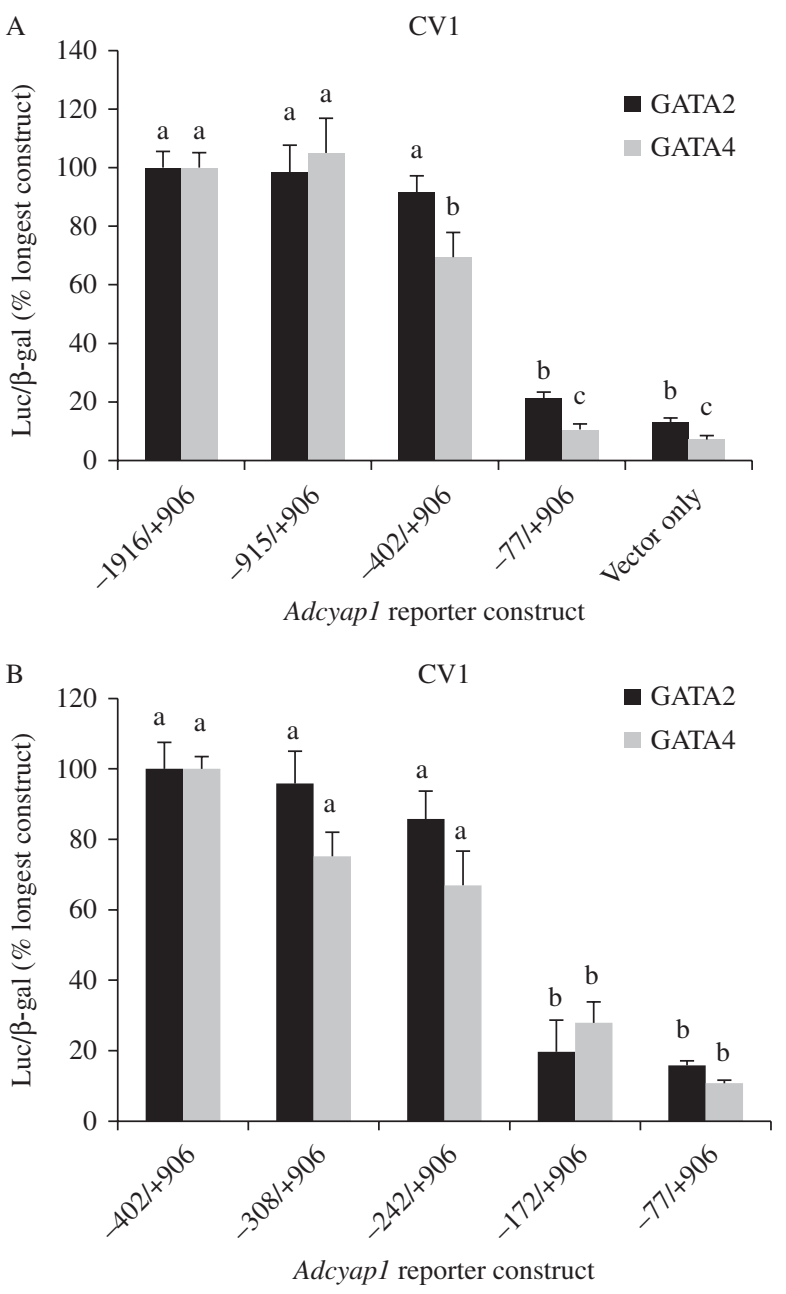

Figure 2

Mapping regions of GATA responsiveness in the Adcyap1 gene promoter. CV1 cells were transiently transfected with various lengths of the rat Adcyap1 promoter-luciferase reporter construct and expression vectors for GATA2 or GATA4. (A) Serial 5'-truncations across region -1916 to +906 relative to the transcriptional start site. Vector only refers to the empty luciferase reporter construct, pGL3. (B) More detailed serial 5'-truncations between positions -402 and -77 relative to the transcriptional start site. Bars with different letters vary significantly within GATA2 or GATA4 results $(P<0.05)$. All experiments were performed a minimum of three times with data expressed as the mean \pm s.E.M.

were also found to interact with this region of the Adcyap1 gene promoter (Fig. 3C). The loss of intensity of this complex with addition of the GATA2 antibody (lane 2) or GATA4 antibody (lane 3) verified the presence of GATA in this complex.

Interestingly, the -191 GATA site is flanked by two sites located at positions -205 and -179 with homology to the consensus CRE cis-element (Fig. 3A). Our laboratory has previously demonstrated CREB binding to the -205 CRE site, with mutation of this site blunting the ability of

Published by Bioscientifica Ltd. 
GNRH to stimulate rat Adcyap1 gene promoter activity (Grafer et al. 2009). An antibody directed against a number of CREB family members supershifted the upper bands, but did not appear to alter the ability of GATA to bind (lane 4).

A

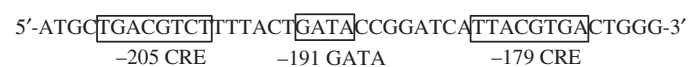

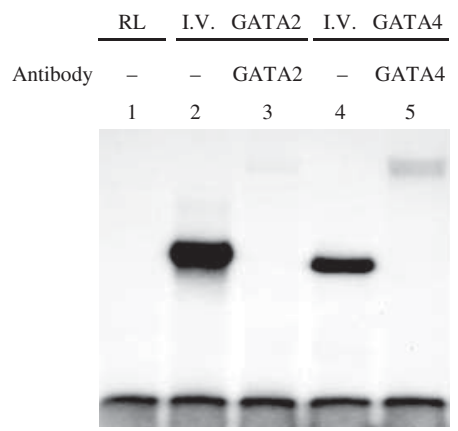

$\mathrm{C}$

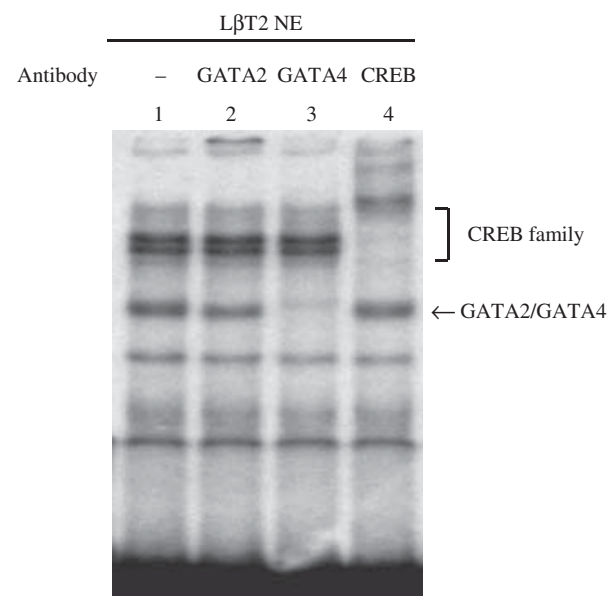

$\mathrm{D}$

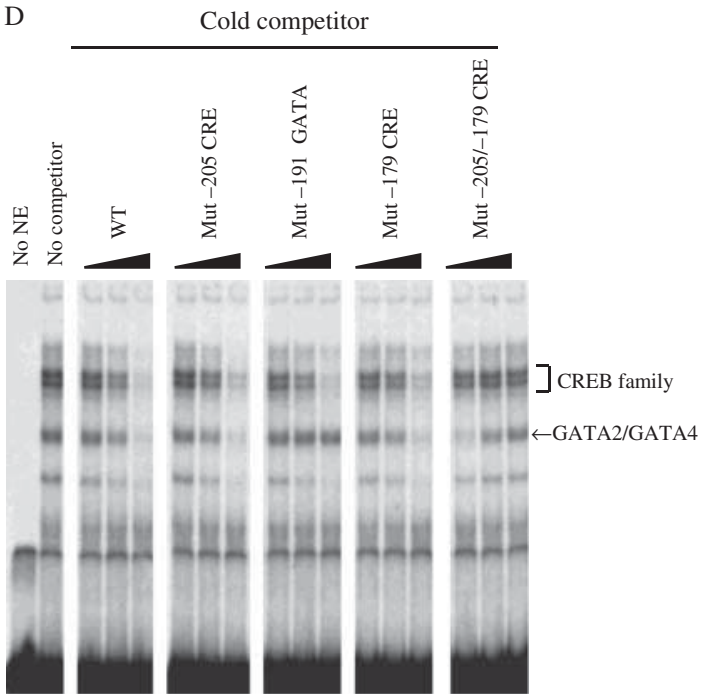

http://jme.endocrinology-journals.org DOI: 10.1530/JME-13-0089

\section{GATA proteins bind to CRE sites which flank the GATA cis-element}

Cold competition EMSA experiments were then performed in which L $\beta$ T2 nuclear extract was incubated with the $-209 /-167$ oligonucleotide probe and excess unlabeled oligonucleotides were added to determine their ability to compete for GATA binding (Fig. 3D). The oligonucleotides which were used contain the CRE and GATA sites present as WT or with the indicated mutations in the putative cis-elements. Mutation in the putative -191 GATA site eliminated the ability of the oligonucleotide to compete for GATA binding, but did not substantially alter the ability of CREB proteins to bind. Conversely, the ability of GATA to interact with the promoter region was not impacted by mutations in the CRE sites. Interestingly, mutations in both CRE sites were required to prevent CREB binding in this region.

Mutations in the -205 CRE, - 191 GATA, and - 179 CRE sites, singly or in combination, decrease GATA2 and GATA4 effect

We next wished to study the functional significance of mutation in the putative GATA and CRE sites on Adcyap1 gene promoter activity. Transient transfection of GATA2 or GATA4 expression vectors and reporter constructs containing the WT full-length $(-1916 /+906)$ rat Adcyap1 gene promoter or constructs containing mutations in these sites were conducted in CV1 fibroblast cells (Fig. 4).

Mutation at the putative -191 GATA cis-element decreased GATA2 and GATA4 stimulated Adcyap1 promoter activity by $50 \pm 5$ and $53 \pm 6 \%$, respectively, compared with WT. Mutation of the -205 CRE decreased GATA2 and GATA4 stimulated Adcyap1 promoter activity by $41 \pm 3$ and $41 \pm 8 \%$, respectively, while mutation at the -179 CRE decreased GATA2 and GATA4 stimulated

\section{Figure 3}

GATA2 and GATA4 bind to the proximal rat Adcyap1 gene promoter on electrophoretic mobility shift assay (EMSA). (A) Depiction of the putative GATA cis-element and flanking CRE sites in the rat Adcyap1 gene promoter. (B) Binding by in vitro translated GATA2, GATA4, or unprogramed reticulocyte lysate $(\mathrm{RL})$ to a ${ }^{32} \mathrm{P}$-labeled oligonucleotide probe spanning positions -209 to -167 in the rat $A d c y a p 1$ gene promoter. (C) Interaction of GATA2 and GATA4 present in L $\beta$ T2 gonadotrope nuclear extracts with the -209/- 167 oligonucleotide probe. Antibodies directed against GATA2, GATA4, or CREB family members were added to the incubation mixture as indicated. (D) $L \beta T 2$ nuclear extract was incubated with the WT $-209 /-167$ Adcyap1 oligonucleotide probe and unlabeled oligonucleotide containing the WT sequence or with mutations in the CRE or GATA sites. Oligonucleotide competitors were added at 200-, 40-, and 8-fold molar excess. Shown are representative EMSA which have been performed a minimum of three times.

Published by Bioscientifica Ltd. 


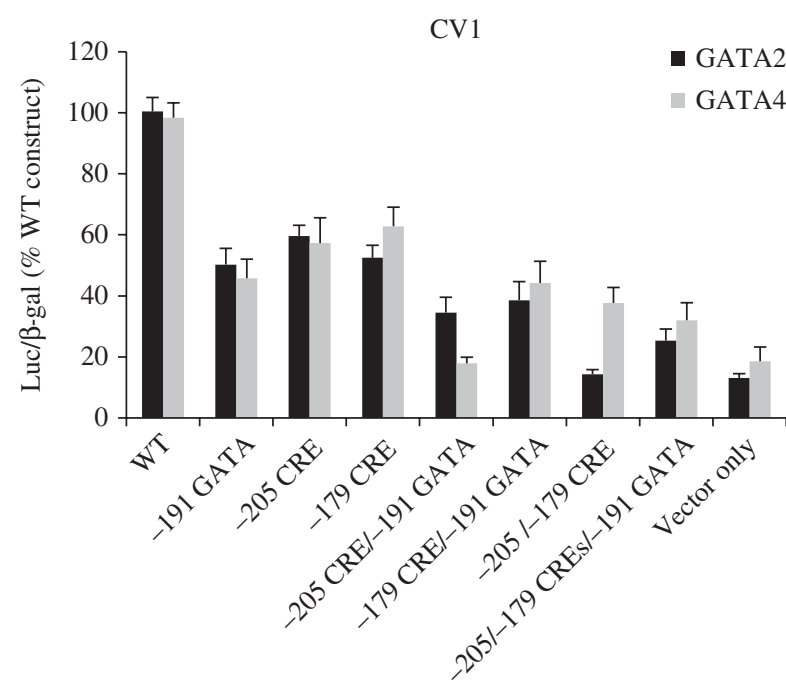

Figure 4

Site-directed mutations in the -191 GATA, -205 CRE, or - 179 CRE sites, either singly or in combination, blunt GATA-stimulated Adcyap1 promoter activity. CV1 cells were transiently transfected with GATA2 or GATA4 expression vectors and the full-length $(-1916 /+906)$ rat Adcyap1 gene promoter (WT) or constructs containing mutations in the - 191 GATA, -205 CRE, and/or -179 CRE sites fused to a luciferase reporter vector. Vector only refers to the empty luciferase reporter construct, pGL3. The response in all mutated constructs was significantly decreased compared with the full-length construct $(P<0.001)$. All experiments were performed a minimum of three times with data expressed as the mean \pm s.E.M.

Adcyap 1 promoter activity by $48 \pm 4$ and $36 \pm 6 \%$ respectively. Combinatorial mutations of the GATA and CRE cis-elements further decreased GATA-stimulated Adcyap1 promoter activity. Compared with the WT, all constructs containing mutations significantly decreased the effects of both GATA2 and GATA4 on Adcyap1 promoter activity $(P<0.001)$. These data demonstrate that the -191 GATA, -205 CRE, and -179 CRE sites all play an important role in GATA-mediated stimulation of the rat Adcyap1 promoter.

\section{GNRH and GATA act cooperatively to stimulate Adcyap1 promoter activity in $\mathrm{L} \beta \mathrm{T} 2$ gonadotrope cells}

Having demonstrated the ability of GATA to increase Adcyap1 promoter activity in the CV1 fibroblast cell line, we now wanted to confirm this observation in gonadotrope L $\beta$ T2 cells. Furthermore, as we have previously shown an important role for GNRH in mediating Adcyap1 promoter activity, the GATA response was tested following treatment with GNRH or vehicle for $6 \mathrm{~h}$. Overexpression of GATA2 (Fig. 5A) or GATA4 (Fig. 5B) significantly increased the stimulatory effect of GNRH on Adcyap1 promoter activity. Note that the GATA response is lower in the gonadotrope cell line as these cells express high levels of endogenous GATA protein (Lo et al. 2011).

As observed in the CV1 cells, a dramatic loss of Adcyap 1 promoter activity occurred with truncation from position -402 to -77 . The simultaneous loss of the GNRH response was expected as this region is known to contain the -205 CRE site as well as a -275 AP1 site, both of which have been shown to be critical for mediating the GNRH effect (Grafer et al. 2009). Additional transfection experiments compared the WT full-length rat Adcyap1 gene promoter to a reporter construct containing a mutation in the -191 GATA site. The presence of this mutation eliminated the ability of both GATA2 and GATA4 to stimulate the Adcyap1 promoter either alone or in the presence of GNRH, while the GNRH response was maintained (Fig. 5C and D). These data demonstrate that an intact -191 GATA site is required for cooperative activation of the rat Adcyap1 promoter by GATA and GNRH treatment.

\section{siRNA knockdown of endogenous GATA2 or GATA4 blunts GNRH-stimulated Adcyap1 gene expression}

As GATA2 and GATA4 significantly increase the ability of GNRH to stimulate Adcyap1 promoter activity, we reasoned that decreasing intracellular expression of these factors using a siRNA approach should blunt the ability of GNRH to stimulate endogenous Adcyap1 gene expression in L $\beta$ T2 cells. As shown in Fig. 6, GNRH-induced Adcyap1 mRNA levels were significantly decreased in the presence of siRNAs directed against Gata2 or Gata4 $(59 \pm 4$ and $52 \pm 3 \%$, respectively, relative to the NTA control siRNA). These data strongly support a requirement for GATA transcription factors in achieving maximal GNRHstimulated Adcyap1 gene expression. No effect was observed on vehicle-treated Adcyap1 expression, likely due to the fact that Adcyap1 mRNA levels are very low in the basal state, preventing the ability to detect a further decrease (data not shown).

The average decrease in Gata2 mRNA levels using siRNAs directed against Gata2 was $51 \pm 4$ and $55 \pm 4 \%$ in the absence and presence of GNRH respectively. The average decrease in Gata 4 mRNA levels using siRNAs directed against Gata 4 was $67 \pm 2$ and $70 \pm 2 \%$ in absence and presence of GNRH respectively (data not shown). We have previously demonstrated a $60-70 \%$ decrease in GATA protein expression using an identical protocol (Lo et al. 2011).

Published by Bioscientifica Ltd. 

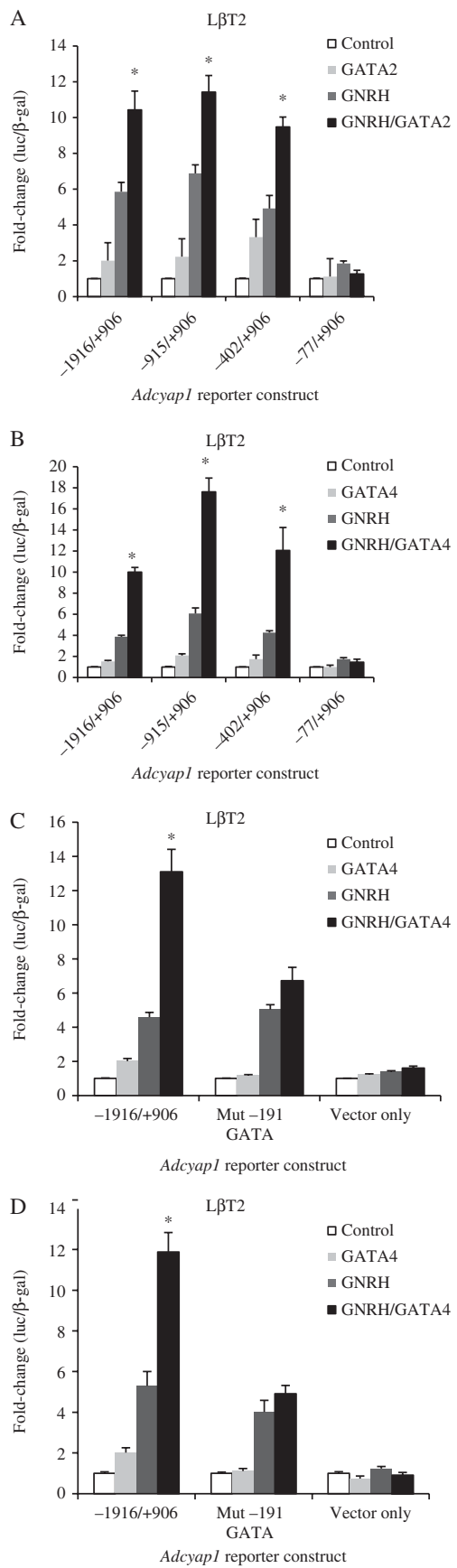

Figure 5

GATA significantly increases GNRH-mediated stimulation of Adcyap1 promoter activity via the -191 GATA cis-element. Gonadotrope L $\beta$ T2 cells were transiently transfected with GATA2 (A) or GATA4 (B) expression vectors and sequential $5^{\prime}$-truncations of the rat Adcyap 1 gene promoter fused to a luciferase reporter followed by treatment with $100 \mathrm{nM}$ GNRH or vehicle for 6 h. L $\beta$ T2 cells were transfected with GATA2 (C) or GATA4 (D) and either the WT $-1916 /+906$ PACAP reporter vector or a construct containing a mutation in the -191 GATA site followed by treatment with $100 \mathrm{nM}$ GNRH or vehicle for $6 \mathrm{~h} . * P<0.001$ vs constructs treated with GNRH alone. All experiments were performed a minimum of three times with data expressed as the mean \pm s.E.M.

\section{Discussion}

Initially described as a hypothalamic neuropeptide, ADCYAP1 is now known to be expressed in a wide range of tissues in which it exerts multiple physiologic effects. Despite growing interest in this peptide, surprisingly little is known about the transcription factors and associated DNA-regulatory regions which mediate expression of the Adcyap1 gene. We have previously reported that GNRH stimulates pituitary Adcyap 1 promoter activity via CREB and the AP1 proteins (Grafer et al. 2009). We now add GATA to the list of transcription factors known to play a critical role in basal and GNRH-stimulated expression of the Adcyap1 gene.

Although highly homologous, GATA family members have been observed to vary in their effects on specific gene promoters as well as their activity within individual cell types and across physiologic states. This functional specificity has been attributed to differences in expression levels of the individual GATA proteins, as well as differences in the expression of cofactors and other transcription factors with which GATA factors are known to interact. In line with these prior observations, our results demonstrate that while GATA2 and GATA4 both markedly increase rat Adcyap1 promoter activity, subtle differences may exist in regards to the importance of specific nucleotide regions for achieving maximal stimulation. For example, deletion from nucleotide position -915 to -402 substantially decreased GATA4-mediated transactivation, but not GATA2, suggesting the presence of a cis-element in this region with specificity for GATA4 (Fig. 2). Characterization of this region will be of interest in future studies.

Our studies demonstrate that the CRE elements which flank the -191 GATA cis-element contribute to GATAmediated stimulation of the Adcyap1 gene promoter, suggesting the presence of complex interactions between CREB and GATA factors on this promoter. Hong et al. (2006) have reported that GATA3 can form proteinprotein bonds with CREB and a similar physical interaction may reasonably be postulated to occur with GATA2 and GATA4. In addition, they demonstrated that mutation of the CRE site markedly blunted the ability of GATA to stimulate expression of the tyrosine hydroxylase gene. Similarly, mutation of the CRE sites in the Adcyap1 promoter sequence blunts GATA-mediated stimulation. The proximity of the CRE and GATA sites suggests that the CREB and GATA proteins may bind to their respective DNA elements and to each other simultaneously to generate a maximal response. Of note, the EMSA

Published by Bioscientifica Ltd 


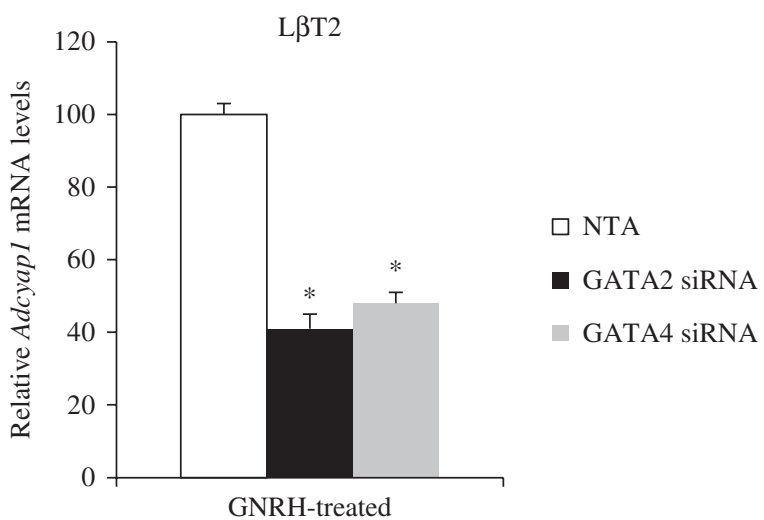

Figure 6

Effect of siRNA knockdown of GATA2 or GATA4 on GNRH-induced Adcyap1 mRNA expression. L $\beta T 2$ cells were transfected with $100 \mathrm{nM}$ of a nontargeting siRNA (NTA) or with $100 \mathrm{nM}$ of siRNA directed against GATA2 or GATA4 followed by treatment with $100 \mathrm{nM}$ GNRH for $6 \mathrm{~h}$. Mouse Adcyap 1 or siRNA target gene mRNA levels were quantified by qPCR. Results are expressed as percent relative to Adcyap1 expression in the GNRH-treated NTA transfected cells and represent the results from three experiments. ${ }^{*} P<0.001$ vs non-targeting control siRNA.

competition experiments did not suggest that binding by one factor was dependent on binding by the other, but subtle effects may be missed by this approach. Further studies with DNA-binding mutants and proteindimerization mutants will be required to characterize the mechanism by which the CRE sites contribute to the GATA response.

Perhaps surprisingly, endogenous Adcyap1 mRNA levels are very low in the L $\beta$ T2 cell line despite the presence of significant amounts of GATA protein. This observation may be a reflection of the balance between stimulatory and inhibitory factors which regulate Adcyap1 promoter activity. At this time, a limited number of transcription factors have been identified which act on this promoter and it is quite possible that these cells also express high levels of a yet unidentified inhibitory factor. Of interest, Adcyap1 mRNA levels are much more readily detected in the $\alpha \mathrm{T} 3-1$ gonadotrope cell line which is generally considered to be less differentiated than the L $\beta$ T2 cell line, suggesting gain of an inhibitory factor with pituitary development (Grafer et al. 2009).

As shown in Fig. 5, GNRH augments GATA-mediated stimulation of Adcyap1 gene promoter activity. Multiple mechanisms can be postulated for this interaction of which the simplest would be a GNRH-mediated increase in GATA protein expression. We have performed preliminary experiments which suggest that $6 \mathrm{~h}$ of GNRH treatment does not alter GATA4 protein expression and may actually decrease GATA2 protein levels in L $\beta$ T2 cells (data not shown). Kamesaki et al. (1996) observed a decrease in GATA1 protein and simultaneous increase in GATA2 protein expression in an erythroid cell line following activation of the PKC system with phorbol ester treatment. As increase in PKC activity results in an arrest in erythroid cell differentiation, they postulated that this quantitative switch in the ratio of GATA proteins was critical for the regulation of genes which mediate differentiation. Our dose-response data suggest that GATA4 may be more active than GATA2 at lower concentrations, albeit with caveats regarding possible differences in protein expression between constructs. Therefore, it is tempting to speculate that a decrease in GATA2 would allow for greater access of the more transcriptionally active GATA4 to the -191 GATA site.

GATA proteins also undergo hormonally mediated post-translational modifications, including acetylation and phosphorylation, which most commonly increase their functional activity (Towatari et al. 1995, Tremblay \& Viger 2003, Hayakawa et al. 2004, Wang et al. 2005). It has been reported that GATA proteins can be phosphorylated following the activation of the PKA, PKC, or MAPK intracellular signaling systems, all pathways known to be activated by GNRH treatment (Liu et al. 2002, Fowkes et al. 2003, Haisenleder et al. 2003, Coss et al. 2007). Using two gonadotrope cell lines, aT3-1 and L $\beta \mathrm{T} 2$, Fowkes et al. (2002) demonstrated an increase in GATA binding to a consensus GATA nucleotide probe following activation of the MAPKK (MEK) signaling system; however, it was not determined whether this was due to an increase in GATA protein levels or alteration in DNA-binding affinity. It is therefore possible that GNRH may increase transcriptional activity of one or both of the GATA proteins via posttranscriptional modifications rather than substantial changes in protein expression.

We have previously demonstrated that GNRHmediated increases in rat Adcyap1 gene promoter activity depend, in large part, on the presence of an intact AP1-like site at position -275 as well as a CRE-like cis-element at position -205 (Grafer et al. 2009). As a general rule, the AP1 family of jun and fos proteins is expressed at low levels before hormonal stimulation, while transcriptional activity of the constitutively expressed CREB family members is modulated by phosphorylation state. Interestingly, GNRH treatment leads to the recruitment of the AP1 proteins, jun and fos, to both of these sites without detectable increases in phospho-CREB binding. These sites may be better described as composite AP1/CRE sites. The ability of the -179 CRE site to bind AP1 proteins was not investigated as the mutation only modestly blunted the

Published by Bioscientifica Ltd. 
GNRH response. In any case, GATA family members have been shown to functionally interact with both AP1 family members and CREB proteins (Kawana et al. 1995, Hong et al. 2006). We, therefore, postulate a complex interaction between GATA proteins and both AP1 and CREB proteins acting at multiple sites in the proximal Adcyap1 gene promoter.

In summary, the data presented here demonstrate a central role for both GATA2 and GATA4 in mediating Adcyap1 gene expression in pituitary gonadotropes. Although we focused on a pituitary cell model, our finding may also be relevant to other cell types. For example, expressions of both ADCYAP1 (Gras et al. 1996, Scaldaferri et al. 1996, Shioda et al. 1996, Lee et al. 1999) and GATA transcription factors (LaVoie 2003) have also been demonstrated in ovarian granulosa cells and thecainterstitial cells. We propose that GATA transcription factors play an instrumental role in the regulation of Adcyap1 gene expression, and therefore, normal reproductive function.

\section{Declaration of interest}

The authors declare that there is no conflict of interest that could be perceived as prejudicing the impartiality of the research reported.

\section{Funding}

This work was supported by the National Institutes of Health Grant R01 HD054782 (to L M H).

\section{Acknowledgements}

We thank Drs Karen Braas and Victor May, who were instrumental in the development of the rat Adcyap1 promoter constructs that launched these studies.

\section{References}

Apostolakis EM, Lanz R \& O’Malley BW 2004 Pituitary adenylate cyclaseactivating peptide: a pivotal modulator of steroid-induced reproductive behavior in female rodents. Molecular Endocrinology 18 173-183. (doi:10.1210/me.2002-0386)

Arimura A \& Shioda S 1995 Pituitary adenylate cyclase activating polypeptide (PACAP) and its receptors: neuroendocrine and endocrine interaction. Frontiers in Neuroendocrinology 16 53-88. (doi:10.1006/frne. 1995.1003)

Burrin JM, Aylwin SJ, Holdstock JG \& Sahye U 1998 Mechanism of action of pituitary adenylate cyclase-activating polypeptide on human glycoprotein hormone $\alpha$-subunit transcription in $\alpha$ T3-1 gonadotropes. Endocrinology 139 1731-1737. (doi:10.1210/en.139.4.1731)

Cheng KW \& Leung PC 2001 Human gonadotropin-releasing hormone receptor gene transcription: up-regulation by $3^{\prime}, 5^{\prime}$-cyclic adenosine monophosphate/protein kinase A pathway. Molecular and Cellular Endocrinology 181 15-26. (doi:10.1016/S0303-7207(01)00480-4)

http://jme.endocrinology-journals.org DOI: 10.1530/JME-13-0089
(C) 2013 Society for Endocrinology Printed in Great Britain
Coss D, Hand CM, Yaphockun KK, Ely HA \& Mellon PL 2007 p38 mitogen-activated protein kinase is critical for synergistic induction of the $\mathrm{FSH}(\beta)$ gene by gonadotropin-releasing hormone and activin through augmentation of c-Fos induction and Smad phosphorylation. Molecular Endocrinology 21 3071-3086. (doi:10.1210/me.2007-0247)

Culler MD \& Paschall CS 1991 Pituitary adenylate cyclase-activating polypeptide (PACAP) potentiates the gonadotropin-releasing activity of luteinizing hormone-releasing hormone. Endocrinology 129 2260-2262. (doi:10.1210/endo-129-4-2260)

Dasen JS, O'Connell SM, Flynn SE, Treier M, Gleiberman AS, Szeto DP, Hooshmand F, Aggarwal AK \& Rosenfeld MG 1999 Reciprocal interactions of Pit1 and GATA2 mediate signaling gradient-induced determination of pituitary cell types. Cell 97 587-598. (doi:10.1016/ S0092-8674(00)80770-9)

Ferris HA, Walsh HE, Stevens J, Fallest PC \& Shupnik MA 2007 Luteinizing hormone $\beta$ promoter stimulation by adenylyl cyclase and cooperation with gonadotropin-releasing hormone 1 in transgenic mice and L $\beta$ T2 Cells. Biology of Reproduction 77 1073-1080. (doi:10.1095/biolreprod. 107.064139)

Fowkes RC, King P \& Burrin JM 2002 Regulation of human glycoprotein hormone $\alpha$-subunit gene transcription in L $\beta$ T2 gonadotropes by protein kinase $\mathrm{C}$ and extracellular signal-regulated kinase $1 / 2$. Biology of Reproduction 67 725-734. (doi:10.1095/biolreprod67.3.725)

Fowkes RC, Sidhu KK, Sosabowski JK, King P \& Burrin JM 2003 Absence of pituitary adenylate cyclase-activating polypeptide-stimulated transcription of the human glycoprotein $\alpha$-subunit gene in L $\beta$ T2 gonadotrophs reveals disrupted cAMP-mediated gene transcription. Journal of Molecular Endocrinology 31 263-278. (doi:10.1677/jme.0. 0310263)

Fujii Y, Okada Y, Moore JP Jr, Dalkin AC \& Winters SJ 2002 Evidence that PACAP and GnRH down-regulate follicle-stimulating hormone- $\beta$ mRNA levels by stimulating follistatin gene expression: effects on folliculostellate cells, gonadotrophs and L $\beta$ T2 gonadotroph cells. Molecular and Cellular Endocrinology 192 55-64. (doi:10.1016/S03037207(02)00109-0)

Grafer CM, Thomas R, Lambrakos L, Montoya I, White S \& Halvorson LM 2009 GnRH stimulates expression of PACAP in the pituitary gonadotropes via both the PKA and PKC signaling systems. Molecular Endocrinology 23 1022-1032. (doi:10.1210/me.2008-0477)

Gras S, Hannibal J, Georg B \& Fahrenkrug J 1996 Transient periovulatory expression of pituitary adenylate cyclase activating peptide in rat ovarian cells. Endocrinology 137 4779-4785. (doi:10.1210/en.137. 11.4779)

Ha CM, Kang JH, Choi EJ, Kim MS, Park JW, Kim Y, Choi WS, Chun SY, Kwon HB \& Lee BJ 2000 Progesterone increases mRNA levels of pituitary adenylate cyclase-activating polypeptide (PACAP) and type I PACAP receptor (PAC(1)) in the rat hypothalamus. Brain Research. Molecular Brain Research 78 59-68. (doi:10.1016/S0169-328X(00)00070-X)

Haisenleder DJ, Ferris HA \& Shupnik MA 2003 The calcium component of gonadotropin-releasing hormone-stimulated luteinizing hormone subunit gene transcription is mediated by calcium/calmodulindependent protein kinase type II. Endocrinology 144 2409-2416. (doi:10.1210/en.2002-0013)

Hart GR, Gowing H \& Burrin JM 1992 effects of a novel hypothalamic peptide, pituitary adenylate cyclase-activating polypeptide, on pituitary hormone release in rats. Journal of Endocrinology 134 33-41. (doi:10.1677/joe.0.1340033)

Hayakawa F, Towatari M, Ozawa Y, Tomita A, Privalsky ML \& Saito H 2004 Functional regulation of GATA-2 by acetylation. Journal of Leukocyte Biology 75 529-540. (doi:10.1189/jlb.0603289)

Heinzlmann A, Kirilly E, Meltzer K, Szabo E, Baba A, Hashimoto H \& Koves K 2008 PACAP is transiently expressed in anterior pituitary gland of rats: in situ hybridization and cell immunoblot assay studies. Peptides 29 571-577. (doi:10.1016/j.peptides.2007.12.009) 
Hong SJ, Huh Y, Chae H, Hong S, Lardaro T \& Kim KS 2006 GATA-3 regulates the transcriptional activity of tyrosine hydroxylase by interacting with CREB. Journal of Neurochemistry 98 773-781. (doi:10.1111/j.1471-4159.2006.03924.x)

Jin L, Tsumanuma I, Ruebel KH, Bayliss JM \& Lloyd RV 2001 Analysis of homogeneous populations of anterior pituitary folliculostellate cells by laser capture microdissection and reverse transcription-polymerase chain reaction. Endocrinology 142 1703-1709. (doi:10.1210/en.142. 5.1703)

Kamesaki H, Michaud GY, Irving SG, Suwabe N, Kamesaki S, Okuma M \& Cossman J 1996 TPA-induced arrest of erythroid differentiation is coupled with downregulation of GATA-1 and upregulation of GATA-2 in an erythroid cell line SAM-1. Blood 87 999-1005.

Kanasaki H, Mutiara S, Oride A, Purwana IN \& Miyazaki K 2009 Pulse frequency-dependent gonadotropin gene expression by adenylate cyclase-activating polypeptide 1 in perifused mouse pituitary gonadotroph L $\beta$ T2 cells. Biology of Reproduction 81 465-472. (doi:10.1095/ biolreprod.108.074765)

Kanasaki H, Purwana IN, Mijiddorj T, Oride A \& Miyazaki K 2011 Possible involvement of PACAP and PACAP type 1 receptor in GnRH-induced FSH $\beta$-subunit gene expression. Regulatory Peptides 167 227-232. (doi:10.1016/j.regpep.2011.02.010)

Kanasaki H, Purwana IN \& Miyazaki K 2013 Possible role of PACAP and its PAC1 receptor in the differential regulation of pituitary LH $\beta$ - and FSH $\beta$-subunit gene expression by pulsatile GnRH stimulation. Biology of Reproduction 88 35. (doi:10.1095/biolreprod.112.105601)

Katayama T, Nakashima M, Kyan H, Murakami N \& Kuroda H 2000 A role of pituitary adenylate cyclase activating polypeptide (PACAP) as a regulator of paracrine interactions between folliculo-stellate cells and gonadotropes through the control of activin-follistatin interactions. Journal of Veterinary Medical Science 62 731-736. (doi:10.1292/ jvms.62.731)

Kawana M, Lee ME, Quertermous EE \& Quertermous T 1995 Cooperative interaction of GATA-2 and AP1 regulates transcription of the endothelin-1 gene. Molecular and Cellular Biology 15 4225-4231.

Ko C, In YH \& Park-Sarge OK 1999 Role of progesterone receptor activation in pituitary adenylate cyclase activating polypeptide gene expression in rat ovary. Endocrinology 140 5185-5194. (doi:10.1210/en.140.11.5185)

Koves K, Kantor O, Scammell JG \& Arimura A 1998 PACAP colocalizes with luteinizing and follicle-stimulating hormone immunoreactivities in the anterior lobe of the pituitary gland. Peptides 19 1069-1072. (doi:10. 1016/S0196-9781(98)00049-7)

Koves K, Kantor O, Molnar J, Heinzlmann A, Szabo E, Szabo F, Nemeskeri A, Horvath J \& Arimura A 2003 The role of PACAP in gonadotropic hormone secretion at hypothalamic and pituitary levels. Journal of Molecular Neuroscience 20 141-152. (doi:10.1385/JMN:20:2:141)

LaVoie HA 2003 The role of GATA in mammalian reproduction. Experimental Biology and Medicine 228 1282-1290.

Lee J, Park HJ, Choi HS, Kwon HB, Arimura A, Lee BJ, Choi WS \& Chun SY 1999 Gonadotropin stimulation of pituitary adenylate cyclaseactivating polypeptide (PACAP) messenger ribonucleic acid in the rat ovary and the role of PACAP as a follicle survival factor. Endocrinology 140 818-826. (doi:10.1210/en.140.2.818)

Liu F, Usui I, Evans LG, Austin DA, Mellon PL, Olefsky JM \& Webster NJ 2002 Involvement of both $\mathrm{G}(\mathrm{q} / 11)$ and $\mathrm{G}(\mathrm{s})$ proteins in gonadotropinreleasing hormone receptor-mediated signaling in L $\beta$ T2 cells. Journal of Biological Chemistry 277 32099-32108. (doi:10.1074/jbc.M203639200)

Lo A, Zheng W, Gong Y, Crochet JR \& Halvorson LM 2011 GATA transcription factors regulate LH $\beta$ gene expression. Journal of Molecular Endocrinology 47 45-58. (doi:10.1530/JME-10-0137)

Merika M \& Orkin SH 1993 DNA-binding specificity of GATA family transcription factors. Molecular and Cellular Biology 13 3999-4010.

Moore JP Jr, Burger LL, Dalkin AC \& Winters SJ 2005 Pituitary adenylate cyclase activating polypeptide messenger RNA in the paraventricular nucleus and anterior pituitary during the rat estrous cycle. Biology of Reproduction 73 491-499. (doi:10.1095/biolreprod.105.041624)
Morelli MB, Barberi M, Gambardella A, Borini A, Cecconi S, Coticchio G \& Canipari R 2008 Characterization, expression, and functional activity of pituitary adenylate cyclase-activating polypeptide and its receptors in human granulosa-luteal cells. Journal of Clinical Endocrinology and Metabolism 93 4924-4932. (doi:10.1210/jc.2007-2621)

Nakagawa R, Sakai Y, Takashima A, Terada T, Kobayashi A \& Maeda M 2001 GATADNA-binding protein expressed in mouse I-10 Leydig testicular tumor cells. Biochemical and Biophysical Research Communications 283 412-416. (doi:10.1006/bbrc.2001.4802)

Ngan ES, Leung PC \& Chow BK 2001 Interplay of pituitary adenylate cyclase-activating polypeptide with a silencer element to regulate the upstream promoter of the human gonadotropin-releasing hormone receptor gene. Molecular and Cellular Endocrinology 176 135-144. (doi:10.1016/S0303-7207(01)00402-6)

Osuga Y, Mitsuhashi N \& Mizuno M 1992 In vivo effect of pituitary adenylate cyclase activating polypeptide 38 (PACAP 38) on the secretion of luteinizing hormone (LH) in male rats. Endocrinologia Japonica 39 153-156. (doi:10.1507/endocrj1954.39.153)

Park JI, Kim WJ, Wang L, Park HJ, Lee J, Park JH, Kwon HB, Tsafriri A \& Chun SY 2000 Involvement of progesterone in gonadotrophin-induced pituitary adenylate cyclase-activating polypeptide gene expression in pre-ovulatory follicles of rat ovary. Molecular Human Reproduction 6 238-245. (doi:10.1093/molehr/6.3.238)

Park JY, Park JH, Park HJ, Lee JY, Lee YI, Lee K \& Chun SY 2001 Stagedependent regulation of ovarian pituitary adenylate cyclase-activating polypeptide mRNA levels by GnRH in cultured rat granulosa cells. Endocrinology 142 3828-3835. (doi:10.1210/en.142.9.3828)

Perrin D, Soling HD, Wuttke W \& Jarry H 1993 The stimulatory effect of pituitary adenylate cyclase activating polypeptide (PACAP) on $\mathrm{LH}$ release from rat pituitary cells in vitro does not involve calcium mobilization. Experimental and Clinical Endocrinology 101 290-296. (doi:10.1055/s-0029-1211246)

Pincas H, Amoyel K, Counis R \& Laverriere JN 2001a Proximal cis-acting elements, including steroidogenic factor 1 , mediate the efficiency of a distal enhancer in the promoter of the rat gonadotropin-releasing hormone receptor gene. Molecular Endocrinology 15 319-337. (doi:10.1210/me.15.2.319)

Pincas H, Laverriere JN \& Counis R $2001 b$ Pituitary adenylate cyclaseactivating polypeptide and cyclic adenosine $3^{\prime}, 5^{\prime}$-monophosphate stimulate the promoter activity of the rat gonadotropin-releasing hormone receptor gene via a bipartite response element in gonadotrope-derived cells. Journal of Biological Chemistry 276 23562-23571. (doi:10.1074/jbc.M100563200)

Purwana IN, Kanasaki H, Oride A, Mijiddorj T, Shintani N, Hashimoto H, Baba A \& Miyazaki K 2010 GnRH-induced PACAP and PAC1 receptor expression in pituitary gonadotrophs: a possible role in the regulation of gonadotropin subunit gene expression. Peptides 31 1748-1755. (doi:10.1016/j.peptides.2010.05.012)

Radleff-Schlimme A, Leonhardt S, Wuttke W \& Jarry H 1998 Evidence for PACAP to be an autocrine factor on gonadotrope cells. Annals of the New York Academy of Sciences 865 486-491. (doi:10.1111/j.1749-6632.1998. tb11222.x)

Robert NM, Miyamoto Y, Taniguchi H \& Viger RS 2006 LRH-1/NR5A2 cooperates with GATA factors to regulate inhibin $\alpha$-subunit promoter activity. Molecular and Cellular Endocrinology 257-258 65-74. (doi:10.1016/j.mce.2006.06.011)

Scaldaferri L, Arora K, Lee SH, Catt KJ \& Moretti C 1996 Expression of PACAP and its type-I receptor isoforms in the rat ovary. Molecular and Cellular Endocrinology 117 227-232. (doi:10.1016/0303-7207(95) 03752-7)

Schomerus E, Poch A, Bunting R, Mason WT \& McArdle CA 1994 Effects of pituitary adenylate cyclase-activating polypeptide in the pituitary: activation of two signal transduction pathways in the gonadotropederived $\alpha$ T3-1 cell line. Endocrinology 134 315-323. (doi:10.1210/ en.134.1.315) http://jme.endocrinology-journals.org

DOI: 10.1530/JME-13-0089
() 2013 Society for Endocrinology Printed in Great Britain 
Sherwood NM, Krueckl SL \& McRory JE 2000 The origin and function of the pituitary adenylate cyclase-activating polypeptide (PACAP)/glucagon superfamily. Endocrine Reviews 21 619-670. (doi:10.1210/er.21.6.619)

Shioda S, Nakai Y, Nakajo S, Nakaya K \& Arimura A 1996 Localization of pituitary adenylate cyclase-activating polypeptide and its type I receptors in the rat ovary: immunohistochemistry and in situ hybridization. Annals of the New York Academy of Sciences 805 677-683. (doi:10.1111/j.1749-6632.1996.tb17540.x)

Steger DJ, Hecht JH \& Mellon PL 1994 GATA-binding proteins regulate the human gonadotropin $\alpha$-subunit gene in the placenta and pituitary gland. Molecular and Cellular Biology 14 5592-5602.

Szabo E, Nemeskeri A, Heinzlmann A, Suzuki N, Arimura A \& Koves K 2002 Cell immunoblot assay study demonstrating the release of PACAP from individual anterior pituitary cells of rats and the effect of PACAP on LH release. Regulatory Peptides 109 75-81. (doi:10.1016/S01670115(02)00186-6)

Towatari M, May GE, Marais R, Perkins GR, Marshall CJ, Cowley S \& Enver T 1995 Regulation of GATA-2 phosphorylation by mitogen-activated protein kinase and interleukin-3. Journal of Biological Chemistry $\mathbf{2 7 0}$ 4101-4107. (doi:10.1074/jbc.270.8.4101)

Tremblay JJ \& Viger RS 2003 Transcription factor GATA-4 is activated by phosphorylation of serine 261 via the cAMP/protein kinase a signaling pathway in gonadal cells. Journal of Biological Chemistry 278 22128-22135. (doi:10.1074/jbc.M213149200)

Tsujii T \& Winters SJ 1995 Effects of pulsatile pituitary adenylate cyclase activating polypeptide (PACAP) on gonadotropin secretion and subunit mRNA levels in perifused rat pituitary cells. Life Sciences $\mathbf{5 6}$ 1103-1111. (doi:10.1016/0024-3205(95)00047-A)

Vaudry D, Gonzalez BJ, Basille M, Yon L, Fournier A \& Vaudry H 2000 Pituitary adenylate cyclase-activating polypeptide and its receptors: from structure to functions. Pharmacological Reviews 52 269-324.

Viger RS, Guittot SM, Anttonen M, Wilson DB \& Heikinheimo M 2008 Role of the GATA family of transcription factors in endocrine development, function, and disease. Molecular Endocrinology 22 781-798. (doi:10.1210/me.2007-0513)

Wang J, Paradis P, Aries A, Komati H, Lefebvre C, Wang H \& Nemer M 2005 Convergence of protein kinase $\mathrm{C}$ and JAK-STAT signaling on transcription factor GATA-4. Molecular and Cellular Biology 25 9829-9844. (doi:10.1128/MCB.25.22.9829-9844.2005)

Winters SJ, Tsujii T \& Attardi B 1996 Effects of GnRH and PACAP on gonadotropin secretion and subunit messenger RNAs. Annals of the New York Academy of Sciences 805 343-352 (discussion 352-354). (doi:10.1111/j.1749-6632.1996.tb17495.x)

Received in final form 15 August 2013

Accepted 6 September 2013

Accepted Preprint published online 9 September 2013
(C) 2013 Society for Endocrinology Printed in Great Britain
Published by Bioscientifica Ltd. 